\title{
TERAPIA FOTODINÂMICA APLICADA NA INATIVAÇÃo DE Pseudomonas aeruginosa COM AZUL DE METILENO
}

\author{
Caio Stachelis Lopes da Silva ${ }^{1}$ \\ André Henrique Correira Pereira ${ }^{2}$ \\ Mirian Aparecida Alvez Freitas ${ }^{3}$ \\ Bianca Albino Siqueira ${ }^{4}$ \\ Letícia Corrêa Fontana ${ }^{5}$ \\ Juliana Ferreira-Strixino ${ }^{6}$
}

Resumo: Pseudomonas aeruginosa é uma bactéria muito abundante no ambiente, podendo infectar principalmente ambientes hospitalares e causar grande risco para pacientes, por apresentar alto perfil de resistência a antibióticos. A Terapia Fotodinâmica (TFD) é um tratamento alternativo que vem se destacando no controle de bactérias em lesões. O objetivo deste estudo é avaliar in vitro, a eficiência do Azul de Metileno como fotossensibilizador (FS) na inativação de $P$. aeruginosa isoladas de material clinico. A concentração do FS foi $0,1 \mathrm{mg} / \mathrm{ml}$ e fluência de $10 \mathrm{~J} / \mathrm{cm}^{2}$ e irradiância de $25 \mathrm{~mW} / \mathrm{cm}^{2}$ em cepas clinicas isoladas de incisão e cateter. No geral a TFD aplicada com o FS em questão foi capaz de inativar cerca de $40 \%$ da bactéria estudada em ambas as cepas.

Palavras-chave: Terapia fotodinâmica; Azul de metileno; Inativação bacteriana.

\footnotetext{
1 Laboratório de Terapia Fotodinâmica/Universidade do Vale do Paraíba - UNIVAP, Brasil. E-mail: caiostachelis@hotmail.com.

2 Laboratório de Terapia Fotodinâmica/Universidade do Vale do Paraíba - UNIVAP, Brasil. E-mail: andre_gcp@hotmail.com.

3 Laboratório de Terapia Fotodinâmica/Universidade do Vale do Paraíba - UNIVAP, Brasil. E-mail: mirianafreitas@hotmail.com.

4 Laboratório de Terapia Fotodinâmica/Universidade do Vale do Paraíba - UNIVAP, Brasil. E-mail: biah_siq@outlook.com.

5 Laboratório de Terapia Fotodinâmica/Universidade do Vale do Paraíba - UNIVAP, Brasil. E-mail: leticia.fontana@yahoo.com.

6 Laboratório de Terapia Fotodinâmica/Universidade do Vale do Paraíba - UNIVAP, Brasil. E-mail: juferreira@univap.br.
} 